\title{
Effect of Goal-Directed Fluid Therapy on Lung Function, Cognitive Function and Inflammatory Response in Patients Undergoing Radical Esophageal Cancer Surgery under One-Lung Ventilation
}

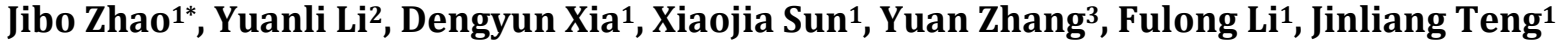 \\ ${ }^{1}$ Department of Anesthesiology, The First Affiliated Hospital of Hebei North University, Zhangjiakou, China \\ ${ }^{2}$ Department of Critical Care Medicine, The First Affiliated Hospital of Hebei North University, Zhangjiakou, China \\ ${ }^{3}$ Operation Room, The First Affiliated Hospital of Hebei North University, Zhangjiakou, China \\ Email: *30994470@qq.com
}

How to cite this paper: Zhao, J.B., Li, Y.L., Xia, D.Y., Sun, X.J., Zhang, Y., Li, F.L. and Teng, J.L. (2021) Effect of Goal-Directed Fluid Therapy on Lung Function, Cognitive Function and Inflammatory Response in Patients Undergoing Radical Esophageal Cancer Surgery under One-Lung Ventilation. Journal of Cancer Therapy, 12, 487-496. https://doi.org/10.4236/jct.2021.129042

Received: July 25, 2021

Accepted: September 5, 2021

Published: September 8, 2021

Copyright $\odot 2021$ by author(s) and Scientific Research Publishing Inc. This work is licensed under the Creative Commons Attribution International License (CC BY 4.0).

http://creativecommons.org/licenses/by/4.0/

\begin{abstract}
Objective: To explore the effects of goal-directed fluid therapy (GDFT) on lung function, cognitive function and inflammatory response in patients undergoing radical esophageal cancer surgery under one-lung ventilation. Methods: Sixty-seven patients undergoing radical esophageal cancer surgery were divided into GDFT group (GDFT therapy) and control group (conventional liquid therapy). The changes in patients' pulmonary function, cognitive function and inflammatory response were evaluated. Results: Both alveolar-arterial oxygen partial pressure difference $\left[\mathrm{P}(\mathrm{A}-\mathrm{a}) \mathrm{O}_{2}\right]$ and respiratory index (RI) increased at one-lung ventilation for 30 minutes $\left(\mathrm{T}_{2}\right)$ and decreased at one-lung ventilation for 60 minutes $\left(\mathrm{T}_{3}\right)$, and after surgery $\left(\mathrm{T}_{4}\right)$ in the two groups, and the GDFT group was lower than the control group $(\mathrm{P}<0.05)$; theoxygenation index (OI) of the two groups decreased at $T_{2}, T_{3}$, and $T_{4}$ compared with that at $\mathrm{T}_{1}$ (before one-lung ventilation), and the GDFT group was higher than the control group $(\mathrm{P}<0.05)$. At $\mathrm{T}_{4}$ and $\mathrm{T}_{5}$, the tumor necrosis factor $\alpha$ (TNF- $\alpha$ ), interleukin 6 (IL-6), central nervous system specific protein $(\mathrm{S} 100 \beta)$, and neuron specific enolase (NSE) in the GDFT group were lower compared to the control group $(\mathrm{P}<0.05)$, while interleukin-10 (IL-10) was higher compared to the control group $(\mathrm{P}<0.05)$; the incidence of perioperative neurocognitive disorder (PND) in the GDFT group was lower than that in the control group $(\mathrm{P}<0.05)$. Conclusion: GDFT can help prevent lung injury during radical esophageal cancer surgery under one-lung ventilation, reduce the body's inflammatory response, and reduce the incidence of
\end{abstract}


perioperative cognitive disorder to a certain extent.

\section{Keywords}

Goal-Directed Fluid Therapy, Radical Resection of Esophageal Cancer, Lung Function, Cognitive Function, Inflammatory Response

\section{Introduction}

One-lung ventilation (OLV) is non-physiological ventilation, which is usually used in thoracic surgery for a favorable surgical field. However, this ventilation may cause lung ischemia/reperfusion injury, increased intrapulmonary shunt, inflammatory response, and further induce acute lung injury, thereby leading to poor prognosis of the patients [1]. Perioperative neurocognitive disorder (PND) is a common disease of central nervous system in elderly surgical patients, which may lead to a prolonged hospital stay and a higher risk of death [2]. Previous studies [3] have shown that the incidence of PND is above $30 \%$ among those receiving OLV. Most of the patients receiving radical surgery for esophageal cancer are elderly, who have reduced organ reserve and are less tolerant to perioperative hemodynamic fluctuation and cerebral oxygen metabolism disorder. Hence, the incidence of complications is higher in the elderly patients receiving OLV. According to a clinical survey [4], poor perioperative fluid management is one risk factor for lung injury and postoperative complication after radical surgery for esophageal cancer. Thus, enhancement of fluid management is clinically significant for these patients. Goal-directed fluid therapy (GDGF) is an individualized choice for fluid replacement based on hemodynamics and blood volume monitoring. A previous study [5] has shown that GDFT can improve microcirculatory perfusion, increase oxygen supply to the tissues and reduce the risk of early cognitive dysfunction. In the present study, we investigated the influence of GDFT on lung function, cognitive function, and inflammatory response in patients who received radical surgery for esophageal cancer under OLV.

\section{Subjects and Methods}

\subsection{Subjects}

Seventy-six patients receiving radical surgery for esophageal cancer were recruited. Inclusion criteria: 1) pathologically confirmed as esophageal cancer and indicated for radical surgery for esophageal cancer under OLV, with surgical time $>60 \mathrm{~min} ; 2$ ) no history of radiochemotherapy before surgery; 3) grade I-II according to the American Society of Anesthesiologists (ASA) physical status classification system; 4) no visual and hearing impairment; 5) age > 18 years; 6) knowing about details of the study with signed informed consent. Exclusion criteria: 1) failure of important organs; 2) respiratory tract infection and chronic 
bronchitis; 3) mental illnesses or cognitive dysfunction; 4) allergic to opioids; 5) incomplete clinicopathological data. The patients were divided into GDFT group and control group using a random number table.

\subsection{Methods}

\subsubsection{Anesthesia}

Radical surgery for esophageal cancer was performed on patients in both groups. Before surgery, the patients were fasted from food and water. After entering the operation room, vital signs were monitored, including heart rate, blood pressure, body temperature, ECG, and blood oxygen saturation. The Narcotrend (Monitor Technik, Bad Bramstedt, Germany) was used to monitor the Narcotrend index (NTI). The CNAP (Noninvasive Arterial Blood Pressure) monitor by CNSystem (Austria) was used to monitor cardiac output (CO), stroke volume variation (SVV), and cardiac index (CI). Anesthetic induction: Intravenous injection of 0.02 $\mathrm{mg} / \mathrm{kg}$ midazolam, $0.4 \mu \mathrm{g} / \mathrm{kg}$ sulfentanyl, $0.6 \mathrm{mg} / \mathrm{kg}$ etomidate, and $0.8 \mathrm{mg} / \mathrm{kg}$ rocuronium bromide was given. Double-lumen endotracheal tube was placed under the guidance of a laryngoscope. After confirming the catheter position by the bronchofibroscope, the ventilator was connected for positive pressure ventilation. For OLV, the tidal volume (VT) was set to $8 \mathrm{~mL} / \mathrm{kg}$, respiratory rate (RR) $10-16$ breaths $/ \mathrm{min}, \mathrm{FiO}_{2}=100 \%$, I:E ratio 1:2, and positive end-expiratory pressure (PEEP) $5 \mathrm{~cm} \mathrm{H} \mathrm{H}_{2} \mathrm{O}$. During surgery, the end tidal carbon dioxide $\left(\mathrm{PETCO}_{2}\right)$ was maintained at $30-40 \mathrm{mmHg}$, with $\mathrm{SpO}_{2}>90 \%$. Right internal jugular vein cannulation was performed after anesthesia was successfully induced. Propofol and remifentanil were intravenously administered using an intravenous infusion pump, with inhalation of $1 \%-2 \%$ sevoflurane. The NTI was maintained at 37 - 46 with continuous central venous pressure (CVP) monitoring. Muscle relaxation was maintained during surgery, with the nasopharyngeal temperature kept above $36^{\circ} \mathrm{C}$.

\subsubsection{Fluid Therapy Regimen}

Control group: Based on preoperative fluid loss, anticipated blood loss during surgery, and compensatory vasodilation, intravenous infusion of 6\% hydroxyethyl starch solution at $5-7 \mathrm{ml} / \mathrm{kg}$ was performed before anesthetic induction. During surgery, the average arterial pressure was maintained at $>65 \mathrm{mmHg}$, CVP at $6-12 \mathrm{~mm} \mathrm{H}_{2} \mathrm{O}$, urine volume $>0.5 \mathrm{~mL} /(\mathrm{kg} \cdot \mathrm{h})$, and heart rate at $60-100$ beats/min.

GDFT group: The fluid replacement was guided by SVV and CI. Before anesthetic induction, the patients were given a continuous intravenous infusion of lactated Ringer's solution at $8 \mathrm{~mL} /(\mathrm{kg} \cdot \mathrm{h})$. The fluid replacement continued if $\mathrm{SVV}<11 \%$ and $\mathrm{CI}>2.5 \mathrm{~L} \cdot\left(\mathrm{min} \cdot \mathrm{m}^{2}\right) ; 6 \%$ hydroxyethyl starch solution was given intravenously at $50 \mathrm{~mL} / \mathrm{min}$ if SVV $>1 \%$, and discontinued once $\mathrm{SVV}<11 \%$. Fluid replacement was stopped if SVV $<9 \%$, which was resumed if SVV $\geq 9 \%$ and kept for $>2 \mathrm{~min}$. In the meantime, CI was maintained above $2.5 \mathrm{~L} \cdot\left(\mathrm{min} \cdot \mathrm{m}^{2}\right)$. If SVV was still $>11 \%$ or $\mathrm{CI}<2.5 \mathrm{~L} \cdot\left(\mathrm{min} \cdot \mathrm{m}^{2}\right)$ after continuous fluid replacement 
for $5 \mathrm{~min}$, small-dose dobutamine was considered. If the intraoperative hemoglobin level was below $80 \mathrm{~g} / \mathrm{L}$ in the two groups, the patients were given erythrocyte suspension. If $\mathrm{HR}$ reduced to below 50 beats/min and lasted for over $1 \mathrm{~min}$, the patients were prescribed $0.5 \mathrm{mg}$ atropine. If the systolic pressure reduced by over $20 \%$ relative to the baseline and lasted for over $1 \mathrm{~min}$, the patients were prescribed $20 \mu \mathrm{g}$ of phenylephrine.

\subsection{Observation Indicators}

1) Lung function and inflammatory response: For each group, $3 \mathrm{ml}$ of radial artery blood was collected before $\operatorname{OLV}\left(\mathrm{T}_{1}\right)$, at $30 \mathrm{~min}$ after $\operatorname{OLV}\left(\mathrm{T}_{2}\right)$, at $60 \mathrm{~min}$ after OLV $\left(\mathrm{T}_{3}\right)$, and at the end of surgery $\left(\mathrm{T}_{4}\right)$, respectively. The partial pressure of carbon dioxide $\left(\mathrm{PCO}_{2}\right)$ and alveolar arterial oxygen partial pressure difference $\left[\mathrm{P}(\mathrm{A}-\mathrm{a}) \mathrm{O}_{2}\right]$ were detected. The respiratory index (RI) and oxygenation index (OI) were calculated. In addition, serum levels of tumor necrosis factor- $\alpha$ (TNF- $\alpha$ ), interleukin 6 (IL-6) and IL-10 were determined at $\mathrm{T}_{1}, \mathrm{~T}_{4}$ and $24 \mathrm{~h}$ after surgery $\left(\mathrm{T}_{5}\right)$, respectively. An enzyme-linked immunosorbent assay was employed to detect serum levels of specific protein $100 \beta$ (S100 $\beta$ ). The electrochemiluminescence assay was carried out to determine serum levels of neuron-specific enolase (NSE).

2) Cognitive function: Mini-Mental State Examination (MMSE) [6] for evaluation of cognitive function was performed on the patients at $24 \mathrm{~h}$ before surgery and at $72 \mathrm{~h}$ after surgery, respectively. PND was considered if the MMSE score was decreased by over 2 .

\subsection{Statistical Analysis}

All statistical analyses were conducted using the SPSS 23.0 software. The counts were expressed as percentages and analyzed by chi-square test or Fisher's exact test. Measurements were expressed as $\bar{x} \pm s$. The data of patients in the same group at different time points were analyzed by repeated-measures analysis of variance. Intergroup comparison was conducted using the two-sample independent $t$-test. $P<0.05$ indicated significant difference.

\section{Results}

\subsection{Sociodemographic and Clinical Characteristics of the Participants}

A total of sixty-seven patients were enrolled, and randomly divided into GDFT group $(n=34)$ and control group $(n=33)$. The baseline demographic and clinical characteristics of the participants are summarized in Table 1 . There were no significant differences in the sex, age, BMI, surgery time and one-lung ventilation time of the participants between the two groups $(\mathrm{P}>0.05)$.

\subsection{Comparison of the Lung Function Indicators between the Two Groups}

There were no significant differences in $\mathrm{PCO}_{2}$ at different time points between 
Table 1. Baseline sociodemographic and clinical characteristics of the participants.

\begin{tabular}{cccccc}
\hline Group & $\begin{array}{c}\text { Sex } \\
(\text { male/ } \\
\text { female })\end{array}$ & $\begin{array}{c}\text { Age } \\
(\text { years })\end{array}$ & $\begin{array}{c}\text { BMI } \\
\left(\mathrm{kg} / \mathrm{m}^{2}\right)\end{array}$ & $\begin{array}{c}\text { Surgery time } \\
(\mathrm{min})\end{array}$ & $\begin{array}{c}\text { One-lung } \\
\text { ventilation } \\
\text { time }(\mathrm{min})\end{array}$ \\
\hline GDFT $(\mathrm{n}=34)$ & $24 / 10$ & $58.26 \pm 7.46$ & $22.13 \pm 2.26$ & $146.82 \pm 25.73$ & $112.56 \pm 24.31$ \\
Control $(\mathrm{n}=33)$ & $26 / 7$ & $57.62 \pm 7.87$ & $21.73 \pm 2.51$ & $141.56 \pm 26.42$ & $114.46 \pm 23.18$ \\
$\chi^{2} / t$ & 0.595 & 0.342 & 0.686 & 0.826 & 0.327 \\
$P$ & 0.441 & 0.734 & 0.495 & 0.412 & 0.745 \\
\hline
\end{tabular}

The data are presented as mean \pm SD. BMI: body mass index; GDFT: goal-directed fluid therapy.

the two groups $(P>0.05)$. At $T_{1}$, there were no significant differences in $\mathrm{P}(\mathrm{A}-\mathrm{a}) \mathrm{O}_{2}$, RI and OI between the two groups $(\mathrm{P}>0.05)$. $\mathrm{P}(\mathrm{A}-\mathrm{a}) \mathrm{O}_{2}$ and $\mathrm{RI}$ of both groups at $\mathrm{T}_{2}$ were increased, but decreased at $\mathrm{T}_{3}$ and $\mathrm{T}_{4}$, which were lower in the GDFT group than in the control group $(\mathrm{P}<0.05)$. OI of the two groups at $\mathrm{T}_{2}, \mathrm{~T}_{3}$ and $\mathrm{T}_{4}$ was lower than that at $\mathrm{T}_{1}$, and it was higher in the GDFT group than in the control group $(\mathrm{P}<0.05)$ (Table 2).

\subsection{Comparison of the Inflammatory Response between the Two Groups}

At $T_{1}$, there were no significant differences in the levels of inflammatory factors between the two groups $(\mathrm{P}>0.05)$. TNF- $\alpha$ and IL- 6 levels of the two groups at $\mathrm{T}_{4}$ and $T_{5}$ were higher than those at $T_{1}$, which were higher in the GDFT group than in the control group $(\mathrm{P}<0.05)$. IL-10 levels of the two groups at $\mathrm{T}_{4}, \mathrm{~T}_{4}$ and $\mathrm{T}_{5}$ were lower than those at $\mathrm{T}_{1}$, which were higher in the GDFT group than in the control group $(\mathrm{P}<0.05)$ (Table 3$)$.

\subsection{Comparison of the Serum S100 $\beta$ and NSE Levels between the Two Groups}

At $T_{1}$, there were no significant differences in serum S100 $\beta$ and NSE levels between the two groups $(\mathrm{P}>0.05)$. Serum $\mathrm{S} 100 \beta$ and NSE levels of the two groups at $\mathrm{T}_{4}$ and $\mathrm{T}_{5}$ were higher than those at $\mathrm{T}_{1}$. In addition, they were significantly higher in the GDFT group than in the control group $(\mathrm{P}<0.05)$ (Table 4).

\subsection{Comparison of the Cognitive Functions between the Two Groups}

PND was found in five patients in the GDFT group, with an incidence of $14.71 \%$ (5/34). In contrast, PND was found in twelve patients in the control group, with an incidence of $36.36 \%$ (12/33). The incidence of PND in the GDFT group was significantly lower than that of the control group $\left(\chi^{2}=4.148, \mathrm{P}=0.042\right)$.

\subsection{Comparison of the Complications between the Two Groups}

The total complication rate was $14.71 \%$ (5/34) in GDFT group, with 3 cases of pulmonary disease, 1 case of empyema and 1 case of anastomotic fistula. In the control group, the total complication rate was $27.27 \%$ (9/33), with 6 cases of 
Table 2. Comparison of the lung function indicators between the two groups $(\bar{x} \pm s)$.

\begin{tabular}{|c|c|c|c|c|c|c|c|c|}
\hline \multirow{2}{*}{ Group } & \multicolumn{4}{|c|}{$\mathrm{P}(\mathrm{A}-\mathrm{a}) \mathrm{O}_{2}(\mathrm{mmHg})$} & \multicolumn{4}{|c|}{$\mathrm{PCO}_{2}(\mathrm{mmHg})$} \\
\hline & $\mathrm{T}_{1}$ & $\mathrm{~T}_{2}$ & $\mathrm{~T}_{3}$ & $\mathrm{~T}_{4}$ & $\mathrm{~T}_{1}$ & $\mathrm{~T}_{2}$ & $\mathrm{~T}_{3}$ & $\mathrm{~T}_{4}$ \\
\hline $\begin{array}{l}\text { GDFT group } \\
\quad(\mathrm{n}=34)\end{array}$ & $420.65 \pm 13.83$ & $482.80 \pm 16.51$ & $383.76 \pm 14.80$ & $351.62 \pm 12.45$ & $38.25 \pm 3.10$ & $38.04 \pm 2.53$ & $37.65 \pm 2.61$ & $38.46 \pm 2.23$ \\
\hline $\begin{array}{l}\text { Control group } \\
\quad(\mathrm{n}=33)\end{array}$ & $414.48 \pm 16.25$ & $564.72 \pm 18.37$ & $469.42 \pm 14.39$ & $427.59 \pm 13.17$ & $38.43 \pm 2.87$ & $37.87 \pm 2.49$ & $37.42 \pm 2.26$ & $38.30 \pm 2.75$ \\
\hline$t$ & 1.675 & 19.211 & 24.010 & 24.270 & 0.246 & 0.277 & 0.385 & 0.262 \\
\hline$P$ & 0.099 & $<0.001$ & $<0.001$ & $<0.001$ & 0.806 & 0.783 & 0.701 & 0.794 \\
\hline$F$ & \multicolumn{4}{|c|}{$F_{\text {intergroup }}=1005.992, F_{\text {time }}=1038.271, F_{\text {interaction }}=141.772$} & \multicolumn{4}{|c|}{$F_{\text {intergroup }}=1.520, F_{\text {time }}=0.088, F_{\text {interaction }}=0.084$} \\
\hline$P$ & \multicolumn{4}{|c|}{$\begin{array}{c}P_{\text {intergroup }}<0.001, P_{\text {time }}<0.001 \\
P_{\text {interaction }}<0.001\end{array}$} & \multicolumn{4}{|c|}{$\begin{array}{c}P_{\text {intergroup }}=0.210, P_{\text {time }}=0.767 \\
P_{\text {interaction }}=0.969\end{array}$} \\
\hline \multirow{2}{*}{ Group } & \multicolumn{4}{|c|}{ RI } & \multicolumn{4}{|c|}{ OI } \\
\hline & $\mathrm{T}_{1}$ & $\mathrm{~T}_{2}$ & $\mathrm{~T}_{3}$ & $\mathrm{~T}_{4}$ & $\mathrm{~T}_{1}$ & $\mathrm{~T}_{2}$ & $\mathrm{~T}_{3}$ & $\mathrm{~T}_{4}$ \\
\hline $\begin{array}{l}\text { GDFT group } \\
\quad(\mathrm{n}=34)\end{array}$ & $0.42 \pm 0.13$ & $1.84 \pm 0.42$ & $1.23 \pm 0.38$ & $0.89 \pm 0.28$ & $480.62 \pm 16.78$ & $342.78 \pm 14.59$ & $302.56 \pm 15.14$ & $388.63 \pm 13.59$ \\
\hline $\begin{array}{l}\text { Control group } \\
\quad(\mathrm{n}=33)\end{array}$ & $0.46 \pm 0.12$ & $2.18 \pm 0.47$ & $1.65 \pm 0.42$ & $1.41 \pm 0.32$ & $482.34 \pm 17.52$ & $276.84 \pm 13.75$ & $258.59 \pm 14.26$ & $326.41 \pm 15.22$ \\
\hline$t$ & 1.308 & 3.124 & 4.295 & 7.085 & 0.410 & 19.026 & 12.229 & 17.663 \\
\hline$P$ & 0.196 & 0.003 & $<0.001$ & $<0.001$ & 0.683 & $<0.001$ & $<0.001$ & $<0.001$ \\
\hline$F$ & \multicolumn{4}{|c|}{$\begin{array}{c}F_{\text {intergroup }}=246.083, F_{\text {time }}=62.838, \\
F_{\text {interaction }}=6.174\end{array}$} & \multicolumn{4}{|c|}{$\begin{array}{c}F_{\text {intergroup }}=2288.705, F_{\text {time }}=528.778 \\
F_{\text {interaction }}=70.320\end{array}$} \\
\hline$P$ & \multicolumn{4}{|c|}{$\begin{array}{c}P_{\text {intergroup }}<0.001, P_{\text {time }}<0.001 \\
P_{\text {interaction }}=0.001\end{array}$} & \multicolumn{4}{|c|}{$\begin{array}{c}P_{\text {intergroup }}<0.001, P_{\text {time }}<0.001, \\
P_{\text {interaction }}<0.001\end{array}$} \\
\hline
\end{tabular}

The data are presented as mean \pm SD. GDFT: goal-directed fluid therapy; OI: oxygenation index; RI: respiratory index.

Table 3. Comparison of the inflammatory response between the two groups $(\bar{x} \pm s, \mathrm{pg} / \mathrm{mL})$.

\begin{tabular}{|c|c|c|c|c|c|c|c|c|c|}
\hline \multirow{2}{*}{ Group } & \multicolumn{3}{|c|}{ TNF- $\alpha$} & \multicolumn{3}{|c|}{ IL-6 } & \multicolumn{3}{|c|}{ IL-10 } \\
\hline & $\mathrm{T}_{1}$ & $\mathrm{~T}_{4}$ & $\mathrm{~T}_{5}$ & $\mathrm{~T}_{1}$ & $\mathrm{~T}_{4}$ & $\mathrm{~T}_{5}$ & $\mathrm{~T}_{1}$ & $\mathrm{~T}_{4}$ & $\mathrm{~T}_{5}$ \\
\hline $\begin{array}{l}\text { GDFT group } \\
\quad(\mathrm{n}=34)\end{array}$ & $18.42 \pm 2.53$ & $65.76 \pm 8.47$ & $141.64 \pm 30.45$ & $8.63 \pm 1.25$ & $55.72 \pm 8.49$ & $52.04 \pm 7.18$ & $93.45 \pm 12.76$ & $575.63 \pm 10.21$ & $89.54 \pm 13.25$ \\
\hline $\begin{array}{l}\text { Control group } \\
\quad(\mathrm{n}=33)\end{array}$ & $17.68 \pm 3.01$ & $96.28 \pm 11.0$ & $5202.79 \pm 37.53$ & $8.91 \pm 1.34$ & $68.53 \pm 11.25$ & $66.36 \pm 10.63$ & $392.18 \pm 14.66$ & $66.42 \pm 9.57$ & $46.77 \pm 8.92$ \\
\hline$t$ & 1.091 & 12.712 & 7.334 & 0.885 & 5.271 & 6.479 & 0.379 & 3.807 & 16.897 \\
\hline$P$ & 0.279 & $<0.001$ & $<0.001$ & 0.380 & $<0.001$ & $<0.001$ & 0.706 & $<0.001$ & $<0.001$ \\
\hline$F$ & $\begin{array}{r}F_{\text {intergroup }}= \\
F\end{array}$ & $\begin{array}{l}=951.880, F_{\text {in }} \\
F_{\text {interaction }}=37 .\end{array}$ & $\begin{array}{l}e=109.164, \\
930\end{array}$ & $\begin{array}{r}F_{\text {intergroup }}= \\
F\end{array}$ & $\begin{array}{l}=991.380, F_{\text {tim }} \\
\text { Finteraction }=16.3\end{array}$ & $\begin{array}{l}e=68.985 \\
62\end{array}$ & $\begin{array}{r}F_{\text {intergroup }}=8 \\
F_{1}\end{array}$ & $\begin{array}{l}88.108, \quad F_{\text {time }}= \\
\text { Finteraction }=58.7 ?\end{array}$ & $\begin{array}{l}=114.482, \\
76\end{array}$ \\
\hline$P$ & $P_{\text {intergrou! }}$ & $\begin{array}{l}\mathrm{p}_{\mathrm{p}}<0.001, P_{\mathrm{ti}} \\
P_{\text {interaction }}<0.0\end{array}$ & $\begin{array}{l}\text { ne }<0.001, \\
01\end{array}$ & $\begin{array}{r}P_{\text {intergroup }} \\
I\end{array}$ & $\begin{array}{l}\mathrm{p}<0.001, P_{\text {time }} \\
P_{\text {interaction }}<0.00\end{array}$ & $<0.001$ & $\begin{array}{r}P_{\text {intergroup }} \\
P\end{array}$ & $\begin{array}{l}\mathrm{p}<0.001, P_{\text {time }} \\
P_{\text {interaction }}<0.00\end{array}$ & $<0.001$ \\
\hline
\end{tabular}

The data are presented as mean \pm SD. GDFT: goal-directed fluid therapy; IL-6: interleukin 6; IL-10: interleukin 10; OI: oxygenation index; RI: respiratory index; TNF- $\alpha$ : tumor necrosis factor. 
Table 4. Comparison of the serum $S 100 \beta$ and NSE levels between the two groups $(\bar{x} \pm s, \mu \mathrm{g} / \mathrm{L})$.

\begin{tabular}{|c|c|c|c|c|c|c|}
\hline \multirow{2}{*}{ Group } & \multicolumn{3}{|c|}{$\mathrm{S} 100 \beta$} & \multicolumn{3}{|c|}{ NSE } \\
\hline & $\mathrm{T}_{1}$ & $\mathrm{~T}_{4}$ & $\mathrm{~T}_{5}$ & $\mathrm{~T}_{1}$ & $\mathrm{~T}_{4}$ & $\mathrm{~T}_{5}$ \\
\hline $\begin{array}{l}\text { Control group } \\
\qquad(\mathrm{n}=33)\end{array}$ & $0.86 \pm 0.31$ & $1.96 \pm 0.67$ & $2.84 \pm 0.65$ & $7.51 \pm 2.24$ & $11.17 \pm 3.26$ & $13.20 \pm 4.78$ \\
\hline$t$ & 0.365 & 4.993 & 9.244 & 0.242 & 3.911 & 3.096 \\
\hline$P$ & 0.716 & 0.000 & 0.000 & 0.810 & 0.000 & 0.003 \\
\hline$F$ & \multicolumn{3}{|c|}{$F_{\text {intergroup }}=140.972, F_{\text {time }}=86.219, F_{\text {interaction }}=24.220$} & \multicolumn{3}{|c|}{$F_{\text {intergroup }}=29.148, F_{\text {time }}=20.003, F_{\text {interaction }}=4.437$} \\
\hline$P$ & \multicolumn{3}{|c|}{$P_{\text {intergroup }}<0.001, P_{\text {time }}<0.001, P_{\text {interaction }}<0.001$} & \multicolumn{3}{|c|}{$P_{\text {intergroup }}<0.001, P_{\text {time }}<0.001, P_{\text {interaction }}=0.013$} \\
\hline
\end{tabular}

The data are presented as mean \pm SD. GDFT: goal-directed fluid therapy; NSE: neuron specific enolase.

lung disease, 1 case of wound infection, 1 case of empyema and 1 case of anastomotic fistula. There was no significant difference in the incidence of total complications between the two groups $\left(\chi^{2}=0.600, \mathrm{P}=0.206\right)$.

\section{Discussion}

Radical surgery for esophageal cancer is common in department of thoracic surgery, and acute lung injury is a common postoperative complication. According to the previous data [7] [8], the overall incidence of acute lung injury after thoracic surgery is $2 \%-12 \%$, and OVL is one reason for acute lung injury. Excessive load during OVL may impede organ function recovery and increase the risk of postoperative pulmonary edema. The contralateral lung is not ventilated during OLV and may suffer from ventilation-perfusion mismatch, which further results in hypoxemia [9]. One study has shown that insufficient cerebral oxygen supply during surgery is an important risk factor for PND in surgical patients [10]. Inflammatory factors generated due to ischemia/reperfusion injury of lung tissues are another risk factor of PND [11]. Restrictive fluid therapy was once considered appropriate for reducing postoperative complications. However, this fluid replacement procedure is guided by CVP. Given the static and hysteretic nature of hemodynamic parameters, CVP is less accurate in assessment of the volume. Therefore, restrictive fluid therapy is associated with an increased risk of occult hypovolemia, cerebral oxygen metabolism disorder and postoperative lung complications. Given the facts above, maintenance of organ perfusion and cerebral oxygen supply-demand balance are the main goals of perioperative fluid management.

GDFT is mainly used to guide fluid replacement based on SVV, which is estimated by pulse profile analysis and based on the influence of the respiratory cycle on cardiac pumping function. SVV, as a functional hemodynamic parameter, can indicate the dynamic trend of hemodynamics under cardiac preload [12]. According to a previous study [13], SVV, as an indicator for assessment in fluid therapy, has a high sensitivity and specificity, and can guide fluid therapy 
in patients receiving OLV. The lung diffusion function can be indicated by $\mathrm{P}(\mathrm{A}-\mathrm{a}) \mathrm{O}_{2}$ and $\mathrm{RI}$, and higher $\mathrm{P}(\mathrm{A}-\mathrm{a}) \mathrm{O}_{2}$ and $\mathrm{RI}$ usually indicate greater severity of lung injury [14]. The normal range of OI is $400-500 \mathrm{mmHg}$. OI is positively correlated with the severity of lung injury, which can be used to assess pulmonary ventilation and oxygenation function [15]. OI is lower under pulmonary dysfunction and ventilation-perfusion mismatch. In the present study, GDFT was performed on some patients who received radical surgery for esophageal cancer under OLV. The results showed that at $\mathrm{T}_{2}, \mathrm{~T}_{3}$ and $\mathrm{T}_{4}, \mathrm{P}(\mathrm{A}-\mathrm{a}) \mathrm{O}_{2}$ and $\mathrm{RI}$ were significantly lower in the GDFT group than in the control group. At $\mathrm{T}_{2}, \mathrm{~T}_{3}$ and $\mathrm{T}_{4}$, OI was significantly higher in the GDFT group than in the control group. It was demonstrated that GDFT could improve lung oxygenation and reduce lung injury in these patients but failed to avoid lung injury. This finding was consistent with $\mathrm{Xu}$ et al.' report [16].

Central nervous system is susceptible to hypoxia. Studies both at home and abroad [17] [18] have shown that perioperative changes in cerebral oxygen saturation are closely related to secondary cognitive dysfunction after surgery. $\mathrm{S} 100 \beta$ protein is a common biochemical marker of central nervous system disorders, which is used to assess the severity of brain injury. The NSE level is usually low in the peripheral blood. As NSE enters the blood circulation via the breached blood-brain barrier in brain injury, the NSE level in the peripheral blood is increased. One study [19] has shown that the NSE level in the peripheral blood is closely related to the severity of brain injury. The serum $S 100 \beta$ and NSE levels in the GDFT group were higher at $T_{4}$ and $T_{5}$ than at $T_{1}$, which were lower than those in the control group. Besides, the incidence of PND in the GDFT group was lower compared to the control group. It was indicated that GDFT could relieve brain injury and reduce the incidence of PND in patients who underwent radical surgery for esophageal cancer under OLV to a certain extent. Similar results were reported by Xie et al. [20]. The possible explanation may be that GDFT effectively increases microperfusion of brain tissues under OLV, thereby improving blood circulation in brain tissues and increasing oxygen supply to avoid secondary brain injury.

Taken together, GDFT can prevent lung injury and alleviate inflammatory response in patients who received radical surgery for esophageal cancer under OLV. Besides, the incidence of PND was reduced by this procedure to a certain degree. However, the present study was a single-center investigation with small sample size. Moreover, PND was only observed for $72 \mathrm{~h}$ after surgery, and long-term follow-up of cognitive functions was absent. Thus, limitations were available in the present study. The findings remain to be further verified by studies with larger sample size and prolonged follow-up.

\section{Conflicts of Interest}

The authors declare no conflicts of interest regarding the publication of this paper. 


\section{Fund Projects}

Research project plan of medical science in Hebei province (20210754).

\section{References}

[1] Arslan-Carlon, V., Tan, K.S., Dalbagni, G., Pedoto, A.C., Herr, H.W., Bochner, B.H., Cha, E.K., Donahue, T.F., Fischer, M. and Donat, S.M. (2020) Goal-Directed versus Standard Fluid Therapy to Decrease Ileus after Open Radical Cystectomy: A Prospective Randomized Controlled Trial. Anesthesiology, 133, 293-303. https://doi.org/10.1097/ALN.0000000000003367

[2] Xu, C., Jiang, C., et al. (2019) Intelligence and Treatment Progress of Neurocognitive Intelligence during Perioperative Period. Critical Care Medicine, 31, 159-162.

[3] Qin, H., Chen, H., Liu, S., et al. (2020) Effect of Nabuyin on Neurocognitive Impairment in Patients with One-Lung Surgery. Chinese Journal of New Drugs and Clinical Remedies, 39, 36-40.

[4] Zhang, P., Wu, L. and Lu, X. (2019) Research Progress of Hemodynamic Monitoring and Surgical Management in Thoracic Surgery. Journal of Chinese Physician, 21, 158-162.

[5] Zhang, N., Liang, M., Zhang, D.D., Xiao, Y.R., Li, Y.Z., Gao, Y.G., Cai, H.D., Lin, X.Z., Lin, C.Z., Zeng, K. and Wu, X.D. (2018) Effect of Goal-Directed Fluid Therapy on Early Cognitive Function in Elderly Patients with Spinal Stenosis: A Case-Control Study. International Journal of Surgery, 54, 201-205.

https://doi.org/10.1016/j.ijsu.2018.04.007

[6] Marioni, R.E., Chatfield, M., Brayne, C. and Matthews, F.E. (2011) Medical Research Council Cognitive Function and Ageing Study Group. The Reliability of Assigning Individuals to Cognitive States Using the Mini Mental-State Examination: A Population-Based Prospective Cohort Study. BMC Medical Research Methodology, 6, Article No. 127. https://doi.org/10.1186/1471-2288-11-127

[7] Wang, P., Yue, C., Wang, H., et al. (2020) Initial Efficacy of Intensity-Modulated Radiotherapy for Esophageal Cancer and Analysis of Influencing Factors of Acute Radiation Lung Injury. Advances in Modern Biomedicine, 20, 183-187.

[8] Lin, M., Shen, Y., Feng, M. and Tan, L. (2019) Is Two Lung Ventilation with Artificial Pneumothorax a Better Choice than One Lung Ventilation in Minimally Invasive Esophagectomy? Journal of Thoracic Disease, 11, S707-S712. https://doi.org/10.21037/jtd.2018.12.08

[9] Joosten, A., Delaporte, A., Ickx, B., Touihri, K., Stany, I., Barvais, L., Van Obbergh, L., Loi, P., Rinehart, J., Cannesson, M. and Van der Linden, P. (2018) Crystalloid versus Colloid for Intraoperative Goal-Directed Fluid Therapy Using a Closed-Loop System: A Randomized, Double-Blinded, Controlled Trial in Major Abdominal Surgery. Anesthesiology, 128, 55-66. https://doi.org/10.1097/ALN.0000000000001936

[10] Li, M.Y., Chen, C., Wang, Z.G., Ke, J.J. and Feng, X.B. (2020) Effect of Nalmefene on Delayed Neurocognitive Recovery in Elderly Patients Undergoing Video-Assisted Thoracic Surgery with One Lung Ventilation. Current Medical Science, 40, 380-388. https://doi.org/10.1007/s11596-020-2170-8

[11] Su, X., Yang, J., Zhao, M., et al. (2018) The Effect of Compound Kushen Injection in Preventing and Treating Acute Radiation Lung Injury after Radiotherapy of Thoracic Malignant Tumor and Its Effect on Serum Related Inflammatory Cytokines. Modern Journal of Integrated Traditional Chinese and Western Medicine, 27, 
1692-1695.

[12] Mukai, A., Suehiro, K., Watanabe, R., Juri, T., Hayashi, Y., Tanaka, K., Fujii, T., Ohira, N., Oda, Y., Okutani, R. and Nishikawa, K. (2020) Impact of Intraoperative Goal-Directed Fluid Therapy on Major Morbidity and Mortality after Transthoracic Oesophagectomy: A Multicentre, Randomised Controlled Trial. British Journal of Anaesthesia, 125, 953-961. https://doi.org/10.1016/j.bja.2020.08.060

[13] Liu, W., Wang, J., Lin, D., et al. (2019) Application of Stroke Volume Variability to Guide Volume Management in lobectomy. Journal of Cardiopulmonary and Vascular Disease, 38, 657-660+664.

[14] Peng, J., Yuan, Y. and Yang, J. (2018) The Effect of Remote Ischemic Preconditioning on the Improvement of Lung Function and Changes in Serum IL-8 Levels in Patients Undergoing Radical Esophageal Cancer Surgery. Hebei Medicine, 40, 77-79.

[15] Liu, Y., Zhao, J. and Shan, X. (2020) Effect of Goal-Directed Fluid Therapy on Regional Cerebral Oxygen Saturation and Hemodynamics in Elderly Patients with One-Lung Ventilation. China Journal of Modern Medicine, 30, 114-118.

[16] Xu, H., Shu, S., Wang, D., et al. (2017) Observation of Intraoperative Pulmonary Function and Central Venous Blood Inflammatory Factor Levels in Patients with One-Lung Ventilation Radical Resection of Lung Cancer with Target-Oriented Liquid Therapy. Shandong Medicine, 57, 94-96.

[17] Zhang, Y., Wu, C. and Xiao, J. (2020) The Effect of Goal-Oriented Volume Therapy on Postoperative Cognitive Dysfunction in Elderly Patients Undergoing Radical Resection of Colorectal Cancer. Journal of Clinical Surgery, 28, 370-373.

[18] Subramaniyan, S. and Terrando, N. (2019) Neuroinflammation and Perioperative Neurocognitive Disorders. Anesthesia and Analgesia, 128, 781-788. https://doi.org/10.1213/ANE.0000000000004053

[19] Schaefer, S.T., Koenigsperger, S., Olotu, C. and Saller, T. (2019) Biomarkers and Postoperative Cognitive Function: Could It Be That Easy? Current Opinion in Anaesthesiology, 32, 92-100. https://doi.org/10.1097/ACO.0000000000000676

[20] Xie, C., Xu, H., Shu, S., et al. (2019) Effects of Goal-Directed Fluid Therapy on Perioperative Neurocognitive Disorders in Elderly Patients with One-Lung Ventilation. Anhui Medicine, 40, 1099-1102. 